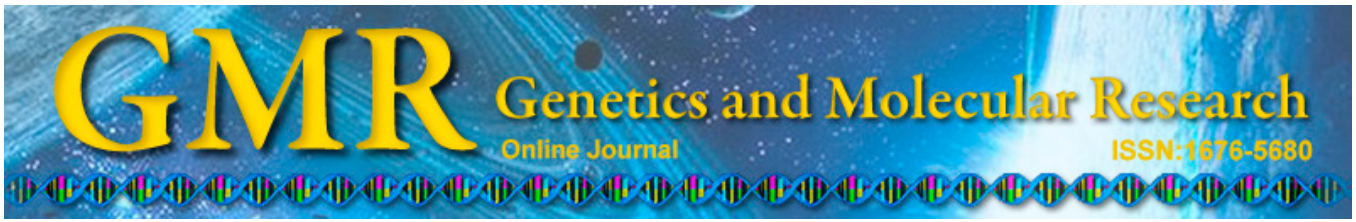

\title{
Analysis of the genetic diversity of beach plums by simple sequence repeat markers
}

\author{
X.M. Wang ${ }^{1}$, W.L. Wu ${ }^{1}$, C.H. Zhang ${ }^{1}$, Y.P. Zhang ${ }^{2}$, W.L. Li ${ }^{1}$ and T. Huang ${ }^{1}$ \\ ${ }^{1}$ Institute of Botany, Jiangsu Province and Chinese Academy of Sciences, Nanjing, \\ Jiangsu, China \\ ${ }^{2}$ College of Horticulture, Anhui Agricultural University, Hefei, Anhui, China \\ Corresponding author: W.L. Li \\ E-mail: Iwlcnbg@mail.cnbg.net
}

Genet. Mol. Res. 14 (3): 9693-9702 (2015)

Received January 7, 2015

Accepted June 25, 2015

Published August 19, 2015

DOI http://dx.doi.org/10.4238/2015.August.19.2

\begin{abstract}
The purpose of this study was to measure the genetic diversity of wild beach plum and cultivated species, and to determine the species relationships using SSRs markers. An analysis of genetic diversity from ten beach plum germplasms was carried out using 11 simple sequence repeat (SSR) primers selected from 35 primers to generate distinct PCR products. From this plant material, 44 allele variations were detected, with 3-5 alleles identified from each primer. The analysis showed that the genetic similarity coefficient varied from $0.721 \pm 0.155$ to $0.848 \pm 0.136$ within each of the ten beach plum germplasms and changed within the range of $0.551 \pm$ 0.084 to $0.695 \pm 0.073$ between any two pairs of germplasms. According to the genetic dissimilarity coefficient matrix, a cluster analysis of SSRs using the unweighted pair group mean average method in the NTSYSpc 2.10 software revealed that the ten germplasms could be divided into two groups at the dissimilarity coefficient of 0.606 . Class I included $77.8,12.5$, 30 , and $33.3 \%$ of MM, MI, NY, and CM, respectively. Class II contains the remaining 9 beach plum germplasms. The markers generated by 11 SSR primers proved very effective in distinguishing the beach plum germplasm resources. It was clear that the geographical distribution did not correspond
\end{abstract}


with the genetic relationships among the different beach plum strains. This result will be of value to beach plum breeding programs.

Key words: Beach plum; Prunus maritima Marshall; SSR markers; Genetic diversity

\section{INTRODUCTION}

The beach plum (Prunus maritima Marshall) is native to the sandy North Atlantic coast, from Newfoundland to North Carolina. Most beach plum populations are found geographically from northern Massachusetts to southern New Jersey (Clark et al., 2000). The beach plum is a stresstolerant shrub that can grow well without much irrigation, even in low-nutrient sandy soils, saline land, old fields, and coastal beaches where many other plants cannot survive (Uva, 2003). The beach plum has a well-developed root system, and for this reason, it can serve as a rootstock to improve the stress tolerance of some tree scions. Aesthetically, it is appreciated for its profuse white blooms in spring and it can maintain their greenery until late autumn. In addition to its ornamental value, the fruit of the beach plum is purple to reddish (or even yellow), up to 1 inch in size, and is used for making jams, jellies, and wine. The beach plum, therefore, is a multipurpose crop. Although the study and utilization of beach plums have a long history and have been the basis for numerous cottage industries, research institutions have shown an increased interest in the last ten years. The leading researchers in this field are from Rutgers University, Cornell University, Cape May (New Jersey) Plant Materials Center of the US Natural Resources Conservation Service, Cooperative Extension of University of Massachusetts, and some private nurseries and farms (Clark et al., 2000).

Breeding of Prunus has been restricted due to the restricted genetic background of commercial cultivars, which also limits commercial production to specific areas and climatic zones. Introgression of genes from related species through inter-specific hybridization has been used in various breeding programs throughout the world to develop better-adapted cultivars and rootstocks (Martinez-Gomez et al., 2003a). Rootstock breeding programs using inter-specific hybridization have introduced useful traits, including size control, self-compatibility, adaptability to new environments, and pest resistance (Martinez-Gomez et al., 2003b). A more thorough evaluation of Prunus maritima could help in planning future hybridization strategies.

Among the different types of molecular markers, microsatellite or simple sequence repeat (SSR) markers are highly prized as molecular markers due to their co-dominance and high levels of polymorphism (Varshney et al., 2006). SSR markers were introduced in the early 1990s and are now being widely used for genetic characterization and diversity analyses of agricultural and horticultural crops. Understanding genetic variation between and within species is relevant to understanding the structures and dynamics of the species. The objective of this study was to analyze the level of polymorphism and genetic relationships between and within ten beach plum germplasms.

\section{MATERIAL AND METHODS}

\section{Plant material}

A total of 84 seedling offspring of ten beach plum genotypes from different states of the USA were used in this research (Table 1). Young leaves were collected from one-year-old branches and stored at $-70^{\circ} \mathrm{C}$ until use. 
Table 1. Origin of the materials used in the study.

\begin{tabular}{llll}
\hline Sample code & Origin & Sample & Sample number \\
\hline UK & Unknown & Individuals from some wild plant & UK1, UK2, UK3, UK4, UK5, UK6, UK7, UK8, UK9 \\
SM & Sandwich Massachusetts & Individuals from some wild plants & SM1, SM2, SM3, SM5, SM4, SM6, SM7, SM8, SM9 \\
MI & Michigan & Individuals from some wild plants & MI1, MI2, MI3, MI4, MI5, MI6, MI7, MI8 \\
NY & State of New York & Individuals from some wild plants & NY1, NY2, NY3, NY4, NY5, NY6, NY7, NY8, NY9, NY10 \\
CM & Cape Code Massachusetts & Individuals from some wild plants & CM1, CM2, CM3, CM4, CM5, CM6, CM7, CM8, CM9 \\
MD & Michigan & Seedling offspring of Dunbars & MD1, MD2, MD3, MD4, MD5, MD6, MD7, MD8, MD9 \\
ME & Michigan & Seedling offspring of Ecos & ME1, ME2, ME3, ME4, ME5, ME6, ME7, ME8 \\
MM & Michigan & Seedling offspring of Mini & MM1, MM2, MM3, MM4, MM5, MM6, MM7, MM8, MM9 \\
MN & Michigan & Seedling offspring of Nana & MN1, MN2, MN3, MN4, MN5, MN6, MN7, MN8, MN9 \\
MW & Michigan & Seedling offspring of Wild Goose & MW1, MW2, MW3, MW4 \\
\hline
\end{tabular}

\section{Primer design}

After pre-screening, 35 primer (Genscript, Nanjing, Jiangsu, China) pairs were chosen that gave distinct, reproducible, and polymorphic amplification products at one or more loci in beach plums. A set of 11 SSR primer pairs were selected on the basis of previous reports of different Prunus species (Rahemi 2012), including ВРРСТ004, ВРРСТ007, ВРРСТ028, ВРРСТ032, ВРРСТ039, СРPCT026, СРPСT039, and UDP98-409 as representatives of peaches (Aranza and Dirlewanger 2002, Cipriani 1999), and СРDCT025, СРDCT027, and СРDCT042 for almonds (Table 2).

Table 2. Simple sequence repeat primers for Prunus species.

\begin{tabular}{|c|c|c|c|c|c|}
\hline No & Primer & Range size (bp) & Ref. & Species & Forward primer $\left(5^{\prime}-3^{\prime}\right)$ \\
\hline 1 & ВРРСТ004 & 200 & Dirlewanger et al. (2002) & Peach & CTGAGTGATCCATTTGCAGG \\
\hline 2 & ВРРСТ007 & $143-15$ & Dirlewanger et al. (2002) & Peach & TCATTGCTCGTCATCAGC \\
\hline 3 & ВРРСТ010 & 131 & Dirlewanger et al. (2004) & Peach & AAAGCACAGCCCATAATGC \\
\hline 4 & ВРРСТ014 & 215 & Dirlewanger et al. (2004) & Peach & TTGTCTGCCTCTCATCTTAACC \\
\hline 5 & ВРРСТ016 & $89-103$ & Dirlewanger et al. (2002) & Peach & GATTGAGAGATTGGGCTGC \\
\hline 6 & ВРРСТ017 & $151-18$ & Dirlewanger et al. (2002) & Peach & TTAAGAGTTTGTGATGGGAACC \\
\hline 7 & ВРРСТ023 & $183-23$ & Dirlewanger et al. (2002) & Peach & TGCAGCTCATTACCTTTTGC \\
\hline 8 & ВРРСТ025 & $178-20$ & Dirlewanger et al. (2002) & Peach & TCCTGCGTAGAAGAAGGTAGC \\
\hline 9 & ВРРСТ026 & $134-14$ & Dirlewanger et al. (2002) & Peach & ATACCTTTGCCACTTGCG \\
\hline 10 & ВРРСТ028 & $155-16$ & Dirlewanger et al. (2002) & Peach & TCAAGTTAGCTGAGGATCGC \\
\hline 11 & ВРРСТ032 & $202-20$ & Dirlewanger et al. (2002) & Peach & TTAAGCCACAACATCCATGAT \\
\hline 12 & ВРРСТ039 & $148-15$ & Dirlewanger et al. (2002) & Peach & ATTACGTACCCTAAAGCTTCTGC \\
\hline 13 & СРDCT004 & $131-15$ & Mnejja et al. (2005) & Almond & TCTCAGGTTCGTATCCCCTCT \\
\hline 14 & СРDCT025 & $172-19$ & Mnejja et al. (2004) & Almond & GACCTCATCAGCATCACCAA \\
\hline 15 & СРDСТ027 & $156-17$ & Mnejja et al. (2005) & Almond & TGAGGAGAGCACTGGAGGAG \\
\hline 16 & СРDCT034 & $157-17$ & Mnejja et al. (2005) & Almond & GAGAACCTTTTGTTTGGCCTTA \\
\hline 17 & СРDCT042 & $164-18$ & Mnejja et al. (2005) & Almond & ACGCGTTACAAGTGAGATGC \\
\hline 18 & СРРСТ002 & 100 & Aranzana et al. (2002) & Almond & GGAGCTGCAATATTGCTG \\
\hline 19 & СРРСТ005 & $122-16$ & Aranzana et al. (2002) & Peach & CATGAACTCTACTCTCCA \\
\hline 20 & СРРСТ006 & $190-21$ & Aranzana et al. (2002) & Peach & ААТTAАСТССАACAGСТССА \\
\hline 21 & СРРСТ008 & $153-19$ & Aranzana et al. (2002) & Peach & GAGCTCTCACGCATTAGTTT \\
\hline 22 & СРРСТ022 & $217-28$ & Aranzana et al. (2002) & Peach & CAATTAGCTAGAGAGAATTATTG \\
\hline 23 & СРРСТ026 & 180 & Aranzana et al. (2002) & Peach & AGACGCAGCACCCAAACTAC \\
\hline 24 & СРРСТ033 & $127-20$ & Aranzana et al. (2002) & Peach & TCAGCAAACTAGAAACAAACC \\
\hline 25 & СРРСТ0З9 & - & Dirlewanger et al. (2004) & Peach & GCACCAGTTCTTCGTCATCTC \\
\hline 26 & CPSCT012 & $126-150$ & Mnejja et al. (2004) & Plum & ACGGGAGACTTTCCCAGAAG \\
\hline 27 & СРSCT034 & 230 & Mnejja et al. (2004) & Plum & AGGTGGACAATAGCCGTGAT \\
\hline 28 & pchgms 5 & 160 & Sosinski et al. (2000) & Peach & CCAGTAGATTTCAACGTCATCTACA \\
\hline 29 & PMS2 & 132-152 & Cantini et al. (2001) & Sweet cherry & CACTGTCTCCCAGGTTAAACT \\
\hline 30 & PS01H03 & - & Sosinski et al. (2000) & Sour cherry & TGAGGAGCATAATGACAGT \\
\hline 31 & UDP96-001 & $122-140$ & Cipriani et al. (1999) & Peach & AGTTTGATTTTCTGATGCATCC \\
\hline 32 & UDP96-019 & $211-222$ & Cipriani et al. (1999) & Peach & TTGGTCATGAGCTAAGAAAACA \\
\hline 33 & UDP98-412 & $101-141$ & Testolin et al. (2000) & Peach & GGGAGGTTACTATGCCATGAAG \\
\hline 34 & UDP98-409 & $126-143$ & Cipriani et al. (1999) & Peach & GCTGATGGGTTTTATGGTTTTC \\
\hline 35 & UDP98-412 & $124-132$ & Testolin et al. (2000) & Peach & AGGGAAAGTTTCTGCTGCAC \\
\hline
\end{tabular}

Eleven pairs of primers marked in italics were the effective primers used in this study. 


\section{Genomic DNA extraction}

Genomic DNA was extracted from the fresh, young leaves using a modified CTAB (cetyltrimethylammonium bromide) method (Murray and Thompson, 1980; Bousquet et al., 1990) by the Plant DNA Extraction Kit (Bio Take Corporation, Beijing, China). The extracted DNA was purified, and, after checking for quality by electrophoresis on a $1 \%$ agarose gel (Genmed, Shanghai, China), was diluted to a final concentration of $20 \mathrm{ng} / \mu \mathrm{L}$ with $1 \mathrm{X}$ TE buffer and stored at $-20^{\circ} \mathrm{C}$.

\section{PCR amplification and verification of genomic DNA}

In total, 11 primer pairs of beach plum SSRs were used for PCR amplification. The PCR amplification was carried out in a $20-\mu \mathrm{L}$ reaction system containing $2 \mu \mathrm{L}$ genomic DNA (20 ng/ $\mu \mathrm{L}), 0.8 \mu \mathrm{L} 10 \mathrm{pmol}$ of each primer, $0.1 \mu \mathrm{L}$ Taq DNA polymerase (5 U/ $\mu \mathrm{L}$, Promega, Madison, WI, USA), $2 \mu \mathrm{L} 10 \mathrm{X}$ buffer, $1.6 \mu \mathrm{L} 25 \mathrm{mM} \mathrm{MgCl}_{2}$, and $1.2 \mu \mathrm{L} 2.5 \mathrm{mM}$ dNTPs. The amplification reaction was performed in an Eppendorf Authorized Thermal Cycler using the following temperature cycling parameters: an initial denaturation for $5 \mathrm{~min}$ at $94^{\circ} \mathrm{C} ; 35$ cycles of denaturation at $94^{\circ} \mathrm{C}$ for $0.5 \mathrm{~min}$, a primer set-specific annealing temperature between $45^{\circ}$ and $68^{\circ} \mathrm{C}$ for $0.5 \mathrm{~min}$, and extension at $72^{\circ} \mathrm{C}$ for $1 \mathrm{~min}$; and a final extension step at $72^{\circ} \mathrm{C}$ for $10 \mathrm{~min}$. The PCR products were resolved by $8 \%$ non-denaturing polyacrylamide gel electrophoresis to check the DNA banding patterns.

\section{Data analysis}

Amplification products were scored as "present" or "absent" and transferred to a binary code with 1 or 0 , respectively. Only distinct, reproducible, and well-resolved SSR fragments could be taken into account and scored as polymorphic markers. Genetic similarities (GS) were calculated using NTSYSpc version 2.10. Next, phylogenetic trees (dendrograms) were constructed using the unweighted pair group mean average method (UPGMA), also in NTSYSpc. Genetic similarity data are reported as the average and standard deviation (SD) that were tabulated in Excel 2003. The coefficient of variation (CV) was calculated as SD/average $\times 100 \%$. Average genetic diversity (AGD), the average number of polymorphic loci in all pairwise comparisons within each species, which was also obtained from NTSYSpc.

\section{RESULTS}

\section{SSR banding patterns}

A total of 35 pairs of SSR primers were used in this study, including 25 pairs specific for the peach, 6 pairs for the apricot, 2 pairs for the plum, 1 pair for the sweet and 1 pair for the sour cherry. Eight DNA samples of the 84 beach plum samples were randomly selected for PCR screening (Figure 1) using the 35 pairs of SSR primers. Four of the 35 pairs of SSR primers could not amplify the beach plum samples, including 2 peach SSR primers (BPPCT023 and PCHGMS55), 1 apricot SSR primer (CPDCT004), and 1 sour cherry SSR primer (PS01H03), with which about $92.0,83.3,100$, and $100 \%$ amplified products successfully with peach, apricot, plum, and sweet cherry samples, respectively. However, only the primers for the peach and apricot resulted in polymorphic bands after amplification, and the effective amplification rate for each was 34.8 and $60 \%$, respectively. 
Only 11 of the 35 primers produced clear PCR products, and the band patterns from the different samples showed clear differences (Table 2). Further, these 11 pairs of SSR primers were used to study the genetic polymorphisms in 84 seedlings from 10 beach plum germplasms. The band patterns generated by BPPCT039 are shown in Figure 2. The results showed that a total of 63 gene loci could be detected from the 84 plant materials with these 11 primer pairs, and 44 polymorphic alleles were detected, and with an average of 4 allelic variations per SSR primer (Table 3). These sites varied by $150-300$ bp (Figure 2). The highest rate of polymorphism $(100 \%)$ was obtained by primers BPPCT039, СРPCT026, and СРPCT039, and the lowest rate of polymorphism, obtained by primers BPPCT004 and CPDCT042, was less than $50 \%$.

\section{CPDCT025}

CPDCT027

СРDCT034

CPDCT042

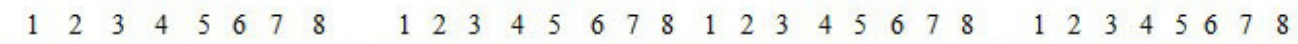

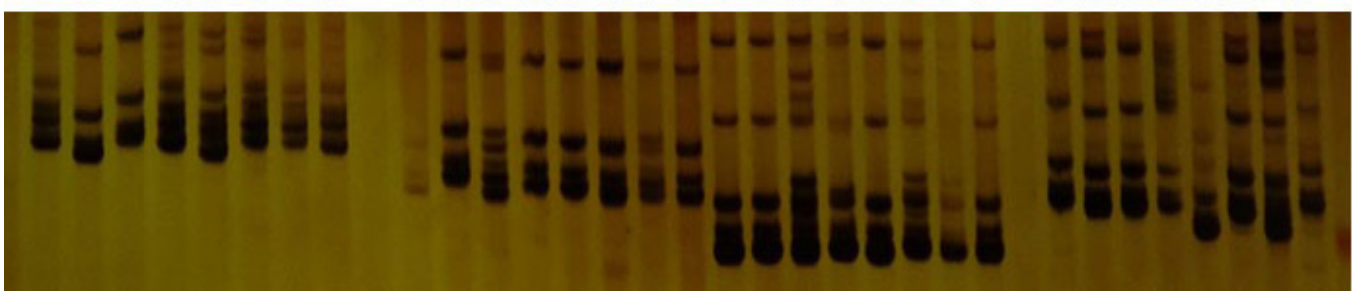

Figure 1. Amplification results of eight DNA samples. Lanes 1-8 correspond to UN8, SM4, MI3, CM4, ME6, MM8, MN9, and UN2, respectively.

\section{5.}

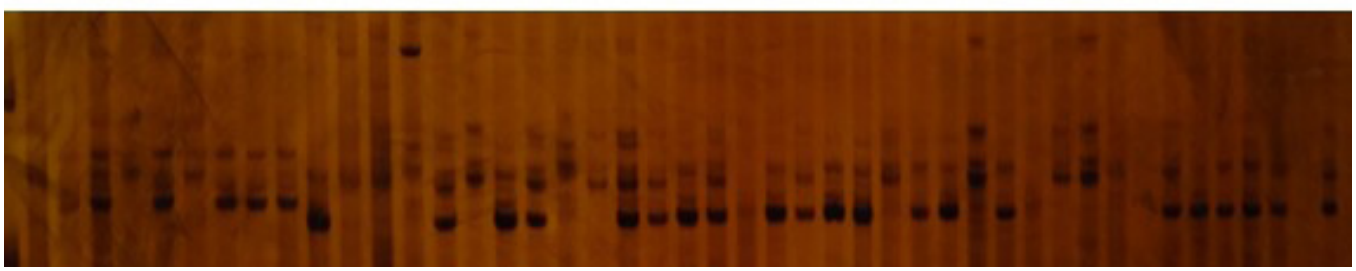

Figure 2. Simple sequence repeat patterns generated by the ВРРСТ039 primer. Lanes 1-45 correspond sequentially toUK1, UK2, UK3, UK4, UK5, UK6, UK7, UK8, UK9, SM1, SM2, SM3, SM5, SM4, SM6, SM7, SM8, SM9, MI1, MI2, MI3, MI4, MI5, MI6, MI7, MI8, NY1, NY2, NY3, NY4, NY5, NY6, NY7, NY8, NY9, NY10, CM1, CM2, CM3, CM4, CM5, $\mathrm{CM} 6, \mathrm{CM} 7, \mathrm{CM} 8$, and CM9.

Table 3. Amplification results of 11 SSR primers.

\begin{tabular}{llccc}
\hline Primer Name & Species & Total No. of loci & No. of polymorphic alleles & Polymorphic proportion \\
\hline BPPCT004 & Peach & 7 & 3 & 42.86 \\
BPPCT007 & Peach & 7 & 4 & 57.14 \\
BPPCT028 & Peach & 6 & 4 & 66.67 \\
BPPCT032 & Peach & 7 & 5 & 71.43 \\
BPPCT039 & Peach & 4 & 4 & 100.00 \\
CPDCT025 & Almond & 5 & 4 & 80.00 \\
CРDCT027 & Almond & 6 & 4 & 66.67 \\
CPDCT042 & Almond & 6 & 3 & 50.00 \\
CPPCT026 & Peach & 5 & 5 & 100.00 \\
CPPCT039 & Peach & 4 & 4 & 100.00 \\
UDP98-409 & Peach & 6 & 4 & 66.67 \\
Total & - & 63 & 44 & 69.84 \\
\hline
\end{tabular}




\section{Genetic analysis}

According to the polymorphic bands resulting from amplification with the SSR primers, the genetic deviations between different germplasm resources were analyzed by NTSYSpc (Figure $3)$. The genetic similarity coefficients of the ten beach plum germplasms were in the range of $0.551 \pm 0.084-0.695 \pm 0.073$, and the mean genetic similarity coefficient was $0.626 \pm 0.032$ (Table 4). This result showed that the genetic similarity between MD (Dunbars) and MM (Mini) was the lowest $(0.551 \pm 0.084)$, while the genetic similarity between SM (Sandwich Massachusetts) and $\mathrm{MI}$ (Michigan) was the highest $(0.695 \pm 0.073)$. The genetic distance within the ten germplasms varied from 15.25 to $27.91 \%$, and the greatest distance was MM (27.91\%), the least was MW (Wild Goose) (15.25\%) (Table 5). The variation coefficients of genetic similarity differed among the samples. The mean variation coefficient between the different beach plum germplasms was $5.1 \%$. However, the mean variation coefficient within one germplasm resource was large (21.5\%), over 4 times that of the other resources (Table 5). These results suggested that regardless of whether the seedlings were progeny of wild beach plums or beach plum cultivars, the genetic distance between the individuals was large.

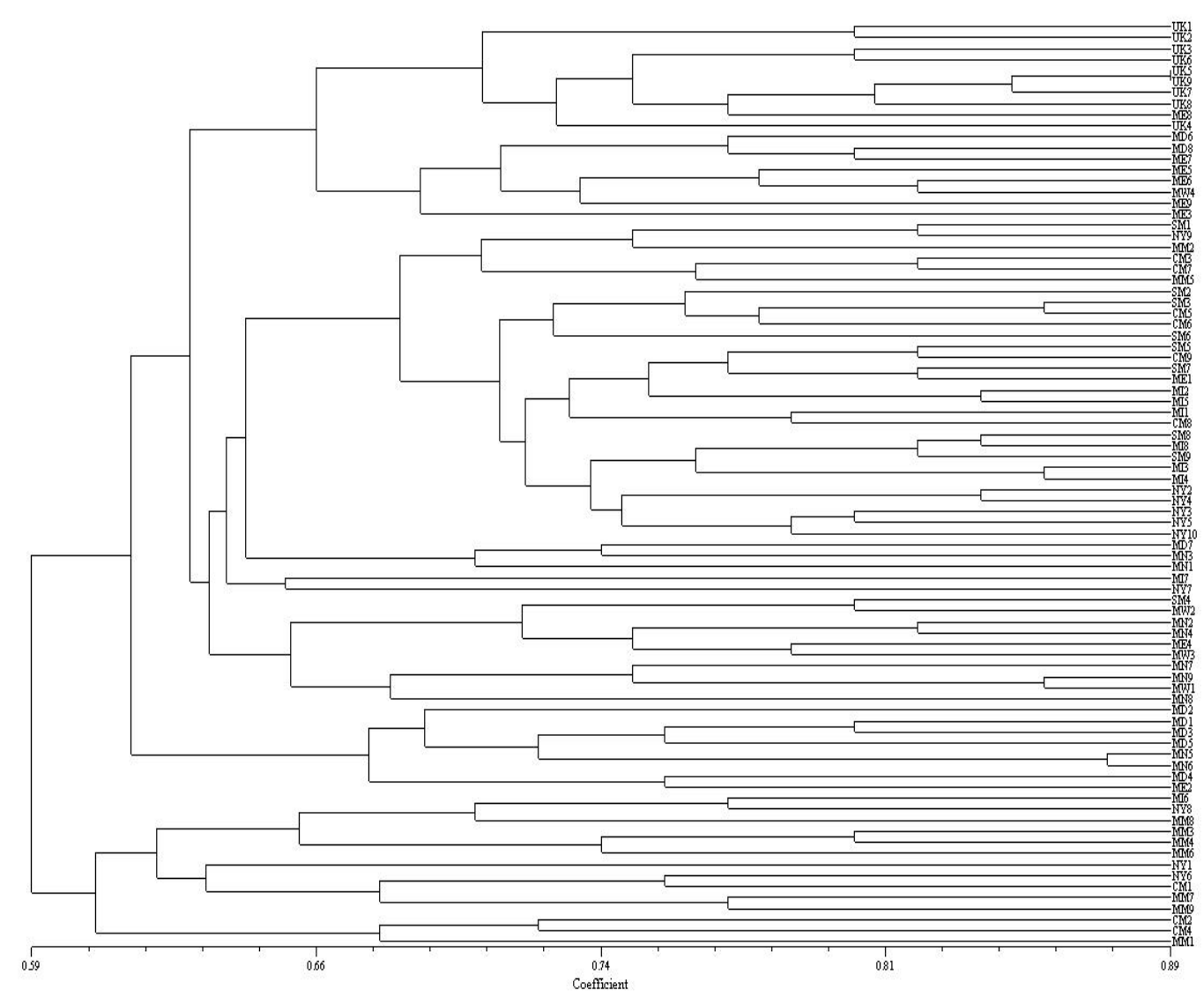

Figure 3. Cluster analysis of 84 beach plum materials based on SSR markers. The numbers in the figure are accession numbers as seen in Table 1. 
Table 4. Genetic similarity between any two pairs of the ten provenances of beach plums based on SSR data.

\begin{tabular}{|c|c|c|c|c|c|c|c|c|c|}
\hline Beach plum & UK & SM & MI & NY & $\mathrm{CM}$ & MD & ME & MM & MN \\
\hline SM & 0.656 & & & & & & & & \\
\hline MI & 0.612 & 0.695 & & & & & & & \\
\hline NY & 0.629 & 0.673 & 0.667 & & & & & & \\
\hline $\mathrm{CM}$ & 0.641 & 0.681 & 0.649 & 0.661 & & & & & \\
\hline MD & 0.627 & 0.609 & 0.605 & 0.579 & 0.563 & & & & \\
\hline ME & 0.658 & 0.643 & 0.622 & 0.623 & 0.635 & 0.633 & & & \\
\hline MM & 0.593 & 0.604 & 0.602 & 0.614 & 0.631 & 0.551 & 0.588 & & \\
\hline MN & 0.598 & 0.656 & 0.631 & 0.624 & 0.624 & 0.617 & 0.635 & 0.584 & \\
\hline MW & 0.627 & 0.673 & 0.602 & 0.621 & 0.629 & 0.608 & 0.659 & 0.582 & 0.675 \\
\hline
\end{tabular}

Table 5. Average genetic diversity (AGD) within the ten provenances of beach plums.

\begin{tabular}{lc}
\hline Beach plum & AGD $(\%)$ \\
\hline UK & 19.49 \\
SM & 21.53 \\
MI & 25.20 \\
NY & 27.09 \\
CM & 24.04 \\
MD & 23.50 \\
ME & 24.85 \\
MM & 27.91 \\
MN & 27.03 \\
MW & 15.25 \\
\hline
\end{tabular}

\section{Genetic relationships among the 84 strains of ten beach plum germplasms}

According to the genetic dissimilarity coefficient matrix, the 84 strains were divided into 2 large classes with a dissimilarity coefficient of 0.606 in the UPGMA tree. Class I included 77.8, $12.5,30$, and $33.3 \%$ of MM, MI, NY, and CM, respectively. Class II contains the remaining 9 beach plum germplasms. Class II could be subdivided into 3 groups at a dissimilarity coefficient of 0.632 in the UPGMA tree. One group contained all the members of UK and $66.7 \%$ of ME, and also contained 10, 25, and $25 \%$ of NY, MD, and MW, respectively. Another group mainly contained 6 beach plum germplasms, including $100 \%$ of SM, $87.5 \%$ of $\mathrm{MI}, 60 \%$ of $\mathrm{NY}, 66.7 \%$ of $\mathrm{CM}, 77.8 \%$ of $\mathrm{MN}, 75 \%$ of $\mathrm{MW}$, and $25 \%, 22.2 \%, 22.2 \%$ of MD, ME, and MM, respectively. The remaining group contained $62.5 \%$ of MD, $22.2 \%$ of $\mathrm{MN}$, and $11.1 \%$ of ME.

Based on the results above, we realized that the geographical distribution is not consistent with the genetic relationships among the different beach plum germplasm resources. The genetic relationships among the wild genotypes were close, apart from 10 strains of UK, 4 other wild genotypes (SM, MI, NY, and CM) could be divided into one group. The genetic relationship between the cultivated species Nana (MN) and Wild Goose (MW) was close, so that in one group, others 3 species (MD, ME, and MM) distributed in 3 different groups alone. Therefore, the relationships between the cultivated species and the wild genotypes are inseparable, which is facilitated by the method of breeding cultivated beach plums that uses artificial selections from wild progeny. Therefore, although MM was the predominate strain in class I, this class also contained some MI, $\mathrm{NY}$, and CM strains. In class II, MN, MW, and wild species were predominant, although there was also a small representation of $\mathrm{MD}, \mathrm{ME}$, and $\mathrm{MM}$. 


\section{DISCUSSION}

It can be difficult and time consuming to distinguish beach plum cultivars based on morphological characteristics alone, and for this reason, it is important to develop molecular markers to aid in cultivar identification. Several marker systems have been applied to perennial ryegrass, including amplified fragment-length polymorphism (AFLPs) (Fang et al., 2005), random amplified polymorphism DNA (RAPDs) (Huff, 1997; Ravi et al., 2003), restriction fragment length polymorphism (RFLPs) (Charmet et al., 1997), and SSRs (Flajoulot et al., 2005; Li et al., 2010). Due to the high level of polymorphism and co-dominance of SSRs markers, these markers are particularly useful for genetic mapping, for studies on genetic variation, and for determining genetic relationships. In this study, we used SSRs markers to fingerprint and evaluate genetic relationships among beach plum cultivars. The high polymorphism may be due to the reasons that most beach plum cultivars develop from seedlings, and the genetic difference among this beach plum cultivars is relatively obvious. This study demonstrated that SSRs primer can be applied efficiently to study beach plum germplasm resources.

Many studies indicate that microsatellite sequences are highly conserved in Prunus (Hormaza, 2002; Serrano et al., 2002), and many SSR primer pairs have been developed for Prunus species and used in their genetic analysis (Cipriani et al., 1999; Aranzana et al., 2002; Dirlewanger et al., 2002; Wang et al., 2011). However, there are no studies on the utilization of SSR primers to analyze beach plum germplasm resources. DNA markers have been shown transfer between plant species, so other Prunus SSR primer pairs were used to identify beach plum germplasms. In this study, SSR amplification products from beach plums were sequenced and compared to those obtained from peaches and almonds. The result showed that the sequences obtained contained the SSR loci and that the number of sequence repeats was different between species. This study also demonstrated that the SSR primer pairs developed for peaches and almonds could be used for the identification of beach plums.

Here, we report the amplification of 11 SSR loci and the use of the SSRs to estimate the genetic diversity in 10 beach plum germplasms. All 84 strains from these 10 germplasms were grouped into 2 main clusters in the dendrogram. From the results, it was clear that the geographical distribution did not correspond with the genetic relationships among the different beach plum strains. This result was different from those previously reported, such as Hurtado et al. (2001), that used the RFLP, RAPD, and AFLP markers to separate 16 apricot cultivars into clusters of genetic similarity that were very similar to clusters of their known geographic origins. This difference merits further study. Genetically, the cultivars "Nana" and "Wild goose" were the closest in the dendrogram, which indicated that these two cultivars shared a common ancestor may have the same origin. In conclusion, the markers generated by 11 SSR primers proved very effective in distinguishing the beach plum germplasm resources. These markers can be used for DNA fingerprinting and estimates of the genetic relatedness of beach plums. The results from this study may be valuable for breeding programs design and genetic resources management of beach plums.

\section{Conflicts of interest}

The authors declare no conflict of interest.

\section{ACKNOWLEDGMENTS}

Research supported by the project "The Study on Introducing, Propagating and Selection of Excellent Germplasm of Beach Plum (Grant \#BE2011324)" of Jiangsu Province, China, and, in 
part, by the Natural Science Fund in Jiangsu Province, China (\#BK2011686). We sincerely thank Professor Ken Asmus (Oikos Tree Crops, Michigan, USA) and Professor Michael S. Dosmann (Living Collections, The Arnold Arboretum of Harvard University) for kindly providing us with the cherished beach plum seeds.

\section{REFERENCES}

Aranzana MJ, Garcia-Mas J, Carbó J and Arús P (2002). Development and variability analysis of microsatellite markers in peach. Plant Breed 121: 87-92.

Bousquet J, Simon L and Lalonde M (1990). DNA amplification from vegetative and sexual tissues of trees using polymerase chain reaction. Can. J. For. Res. 20: 254-257.

Cantini C, lezzoni AF, Lamboy WF, Boritzki M, et al. (2001). DNA fingerprinting of tetraploid cherry germplasm using SSR. J. Am. Sci. Hort. Sci. 126: 205-209.

Charmet G, Ravel C and Balfourier F (1997). Phylogenetic analysis in the Festuca-Lolium complex using molecular markers and ITS rDNA. Theor. Appl. Genet. 94: 1038-1046.

Cipriani G, Lot G, Huang WG, Marrazzo MT, et al. (1999). AG/GT and AG/CT microsatellite repeats in peach [Prunus persica (L) Batsch]: isolation, characterization and cross-species amplification in Prunus. Theor. Appl. Genet. 99: 65-72.

Clark R, Simser DH and Uva RH (2000). The beach plum: a history and grower's guide. Cape Cod Cooperative Extension, Barnstable, 1-14.

Dirlewanger E, Cosson P, Tavaud M, Aranzana MJ, et al. (2002). Development of microsatellite markers in peach [Prunus persica (L.) Batsch] and their use in genetic diversity analysis in peach and sweet cherry (Prunus avium L.). Theor. Appl. Genet. 105: 127-138.

Dirlewanger E, Graziano E, Joobeur T, Garriga-Calderé F, et al. (2004). Comparative mapping and marker-assisted selection in Rosaceae fruit crops. PNAS 101: 9891-9896.

Fang J, Qiao Y and Zhang Z (2005). Genotyping fruiting mei (Prunus mume Sieb. et Zucc.) cultivars using amplified fragmentlength polymorphism markers. Hort. Sci. 40: 325-328.

Flajoulot S, Ronfort J, Baudouin P, Barre P, et al. (2005). Genetic diversity among alfalfa (Medicago sativa) cultivars coming from a breeding program, using SSR markers. Theor. Appl. Genet. 111: 1420-1429.

Hormaza JI (2002). Molecular characterization and similarity relationships among apricot (Prunus armeniaca L.) genotypes using simple sequence repeats. Theor. Appl. Genet. 104: 321-328.

Huff DR (1997). RAPD characterization of heterogeneous perennial ryegrass cultivars. Crop Sci. 37: 557-564.

Hurtado MA, Badenes ML, Liácer G, Westman A, et al. (2001). Contribution to apricot genetic analysis with RFLP, RAPD and AFLP markers. Acta Hort. 546: 417-420.

Li XY, Shangguan LF, Song CN, Wang C, et al. (2010). Analysis of expressed sequence tags from Prunus mume flower and fruit and development of simple sequence repeat markers. BMC Genetics 11: 66.

Martínez-Gómez P, Arulsekar S, Potter D and Gradziel TM (2003a). An extended interspecific gene pool available to peach and almond breeding as characterized using simple sequence repeat (SSR) markers. Euphytica 131: 313-322.

Martínez-Gómez P, Arulsekar S, Potter D and Gradziel TM (2003b). Relationships among peach and almond and related species as detected by SSR markers. J. Am. Soc. Hort. Sci. 128: 667-671.

Mnejja M, Garcia-Mas J, Howad W, Badenes ML, et al. (2004). Simple-sequence repeat (SSR) markers of Japanese plum (Prunus salicina Lindl.) are highly polymorphic and transferable to peach and almond. Mol. Ecol. Notes 4: $163-166$.

Mnejja M, Garcia-Mas J, Howad W and Arús P (2005). Development and transportability across Prunus species of 42 polymorphic almond microsatellites. Mol. Ecol. Notes 5: 531-535.

Murray MG and Thompson WF (1980). Rapid isolation of high molecular weight plant DNA. Nucl. Acid. Res. 8: $4321-4325$.

Rahemi A, Fatahi R, Ebadi A, Taghavi T, et al. (2012). Genetic diversity of some wild almonds and related Prunus species revealed by SSR and EST-SSR molecular markers. Plant Syst Evol. 298: 173-192.

Ravi M, Geethanjali S, Sameeyafarheen F and Maheswaran M (2003). Molecular marker based genetic diversity analysis in rice (Oryza sativa L.) using RAPD and SSR markers. Euphytica 133: 243-252.

Serrano BB, Gomez-Aparisi J and Hormaza JI (2002). Molecular fingerprinting of Prunus rootstocks using SSRs. J. Hor. Sci. Biol. 77: 368-372.

Sosinski B, Gannavarapu M, Hager LD, Beck LE, et al. (2000). Characterization of microsatellite markers in peach [Prunus persica (L.) Batsch]. Theor. Appl. Genet. 101: 421-428.

Testolin R, Marrazzo T, Cipriani G, Quarta R, et al. (2000). Microsatellite DNA in peach (Prunus persica L. Batsch) and its use in fingerprinting and testing the genetic origin of cultivars. Genome 43: 512-520. 
Uva RH (2003). Growth and yield of beach plum in horticultural, land restoration, and ecological systems. Doctoral thesis, Cornell University, Ithaca.

Varshney RK, Sharma PC, Gupta PK, Balyan HS, et al. (2006). Low level of polymorphism detected by SSR probes in bread wheat. Plant Breed. 117: 182-184.

Wang YJ, Li XY, Han J, Fang WM, et al. (2011). Analysis of genetic relationships and identification of flowering-mei cultivars using EST-SSR markers developed from apricot and fruiting-mei. Sci. Hort. 132: 12-17. 